\title{
PROBABILITY CALIBRATION OF LOAD DURATION MODIFICATION FACTOR FOR TIMBER ROOFS IN THE POLISH MOUNTAIN ZONES
}

\author{
T. DOMAŃSKI ${ }^{1}$
}

\begin{abstract}
The resistance parameters of timber structures decrease with time. It depends on the type of load and timber classes. Strength reduction effects, referred to as creep-rupture effects, due to long term loading at high stress ratio levels are known for many materials. Timber materials are highly affected by this reduction in strength with duration of load. Characteristic values of load duration and load duration factors are calibrated by means of using probabilistic methods. Three damage accumulation models are considered, that is Gerhard [1] model, Barret, Foschi[2] and Foshi Yao [3] models. The reliability is estimated by means of using representative short- and long-term limit states. Time variant reliability aspects are taken into account using a simple representative limit state with time variant strength and simulation of whole life time load processes. The parameters in these models are fitted by the Maximum Likelihood Methods using the data relevant for Polish structural timber. Based on Polish snow data over 45 years from mountain zone in: Zakopane - Tatra, Świeradów - Karkonosze, Lesko - Bieszczady, the snow load process parameters have been estimated. The reliability is evaluated using representative short - and long -term limit states, load duration factor $k_{m o d}$ is obtained using the probabilistic model.
\end{abstract}

Keywords: reliability, snow wind loads, timber structures

\section{INTRODUCTION}

The effect of sustained stress on timber bending strength has been recognized since at least 1850 . Wood developed a time strength curve that was incorporated into the wood design procedure. This curve, often referred to as the "Madison curve", is still in use, Rosowsky [4] During the last decades structural reliability methods have been further developed, improved and adopted and are now at a level where they are being applied in practical engineering problems. The basic knowledge concerning the actions on structures and timber material characteristics has been developed to increased knowledge, better measuring techniques and international research cooperation.

This knowledge has now reached a level where it enables designers to take into account uncertainties in material properties and actions in assessing the load carrying capacity, serviceability and service life of timber structures and connections. Now, most

${ }^{1}$ Institute of Building Materials and Structures, Cracow University of Technology, Poland, e-mail: doman@pk.edu.p 
building codes are based on a probabilistic safety approach. The code formats are deterministic with connections to reliability design achieved through failure probability, partial safety factors and characteristic values Kowal [5], Maślak [6]. Partial safety factors are calibrated for standard cases against probabilistic analyses for similar cases. The condition for calibration - that is the probabilistic analysis and deterministic code should be fulfilled with the same safety requirements Woliński [7]. Thereby, the required safety is usually not accomplished by using probabilistic theories in everyday designing process. Timber is a rather complex building material. The timber material characteristics depend on the specific wood species, the geographical location where the wood has been grown and furthermore on the local growing conditions. Timber is an orthotropic material and it consists of high strength grains which are predominantly orientated along the longitudinal axis of a tree. Material characteristics - the ultimate bending stress and the bending stiffness depend on the orientation of the moment axis to the grain direction. Irregularities in regard to grain direction, knots and fissures become highly decisive for load bearing capacity of a timber structural element. Only in very small test specimens it is possible to avoid these irregularities - with so-called clear wood specimen it is possible to investigate the orthotropic material properties of timber.

Timber materials are highly affected by reduction in strength with duration of load in time. Therefore the design of timber structures utilizes a strength reduction factor to reduce characteristic short-term strength. The Eurocode for timber structures EC 5 refers to this strength modification with a load duration factor, $k_{\text {mod }}$ Traditionally, the load duration factor is determined empirically by experience on timber structures, but there are probabilistic methods connected with damage accumulation models to estimate factor $k_{\text {mod }}$ as well Kohler, Sorensen, Faber [8], Sorensen, Svensson, Stang [9], Faber, Kohler, Sorensen [10]. The load duration factor $k_{\bmod }$ is defined in EC 5 [11] as a factor which takes into account the effects of load duration and ambient climate on the strength parameters of structural timber members. Gerhards [1] damage accumulation model is taken into consideration. The mechanism leading to the reduction in strength of a timber member under sustained load is a creep rupture. This could arise from propagation of voids in the microstructure of the timber at a stress level lower than the short-term strength. A number of models of creep rupture, involving a damage state variable (similar to that used in the analysis of metal fatigue), have been proposed to assess damage accumulation in wood structural members subject to loading histories, typically modeled as renewal pulse process. The basic model Ellingwood [12] has the following form Eq. (1.1).

$$
d \alpha / d t=F[s(t)],
$$

where $t$ - time, $\alpha$ - the damage state variable which ranges from 0 (no damage) to 1 (failure), the function $F($.) has two constants that must be determined from test data, and $s(t)$ - the ratio of the applied stress to the failure stress under short-term ramp loading. 


\section{Design Resistance AND Ultimate Limit State For timber MEMBers}

When dealing with timber and wood-related product structures, in line with the requirements of EC0[13], the design value of a resistance is $R_{d}$ expressed in EC5[11], as

$$
R_{d}=k_{\text {mod }} \frac{R_{k}}{\gamma_{M}},
$$

where $k_{\text {mod }}$ is a modification factor that takes into account the effect of load duration and moisture content in timber, $\gamma_{M}$ is the partial factor for a material property at the Ultimate Limit State (ULS) condition, and $R_{k}$ is the characteristic value of the load-carrying capacity at the ULS.

In general, the resistance properties are defined in EC5 [11] as $F$ functions and the more representative expression for the design resistance for a timber or wood-related product is

$$
F_{R d}=k_{\text {mod }} \frac{F_{R k}}{\gamma_{M}} .
$$

Table 1.

\begin{tabular}{|c|c|c|c|c|c|}
\hline \multirow{2}{*}{$\begin{array}{l}\text { Load-duration } \\
\text { class }\end{array}$} & \multirow{2}{*}{$\begin{array}{l}\text { Order of accumu- } \\
\text { lated duration of } \\
\text { characteristic load }\end{array}$} & \multirow{2}{*}{$\begin{array}{l}\text { Examples of } \\
\text { loading }\end{array}$} & \multicolumn{3}{|c|}{ Service classes } \\
\hline & & & $\begin{array}{c}\text { class } 1 \\
M C<12 \%\end{array}$ & $\begin{array}{c}\text { class } 2 \\
12 \%<\mathrm{MC}<20 \%\end{array}$ & $\begin{array}{c}\text { class } 2 \\
M C>20 \%\end{array}$ \\
\hline Permanent & $\begin{array}{l}\text { more than } \\
10 \text { years }\end{array}$ & self weight & 0.60 & 0.60 & 0.50 \\
\hline Long-term & $\begin{array}{l}6 \text { month } \\
\text { to } 10 \text { years }\end{array}$ & storage & 0.70 & 0.70 & 0.65 \\
\hline Medium-term & $\begin{array}{l}1 \text { week } \\
\text { to } 6 \text { months }\end{array}$ & $\begin{array}{l}\text { imposed } \\
\text { floor load, } \\
\text { snow }\end{array}$ & 0.80 & 0.80 & 0.70 \\
\hline Short-term & less than one week & wind & 0.90 & 0.90 & 0.70 \\
\hline Instantaneous & & $\begin{array}{l}\text { accidental } \\
\text { load }\end{array}$ & 1.10 & 1.10 & 0.90 \\
\hline
\end{tabular}

Modification factor $k_{\mathrm{mod}}$

For timber or wood product structures, ULS will generally be relevant and is taken into account in EC5 by the Strength (STR) requirements. Load combinations are applied at each relevant ULS and by the application of the partial factor method it must be verified that the design value of the effect of the design actions is less than or equal to the design value of the equivalent resistance. For example, considering the strength verification of the structure and its elements at the STR ULS, the requirement will be 


$$
E_{f d} \leq F_{R d} .
$$

In this paper, the combination of actions on timber roofs for persistent or transient design situations (referred to in EC0 [13] as the fundamental combinations), were used in the combination given in equation (6.10) in EC0 [13].

To determine the load case producing the greatest design effect (i.e. the maximum bending moment, shear force, etc.), the load combination equations were applied in turn with each variable action acting as the leading variable, acting on timber structures Porteus, Kermani [14]. Also, where the variable loads were not related, all possible combinations were considered. For example, considering the STR limit state for a timber roof rafter loaded by its own weight, $G_{k, 1}$, roof covering, $G_{k, 2}$, a snow (medium-term duration), $Q_{k, 1}$, and a wind (short-term duration), $Q_{k, 2}$. Adopting equation (6.10) EC0, the alternative loading conditions that have to be considered to determine an effect, $E f$, e.g. a bending moment, are

$$
\begin{aligned}
& 1.35\left(G_{k 1}+G_{k 2}\right) \rightarrow E f_{1}, 1.35\left(G_{k 1}+G_{k 2}\right)+1.5 Q_{k 1} \rightarrow E f_{2}, 1.00\left(G_{k 1}+G_{k 2}\right)+1.5 Q_{k 2} \rightarrow E f_{3} \\
& 1.35\left(G_{k 1}+G_{k 2}\right)+1.5 Q_{k 1}+1.5 \psi_{0,2} Q_{k 2} \rightarrow E f_{4}, 1.35\left(G_{k 1}+G_{k 2}\right)+1.5 Q_{k 1}+1.5 \psi_{0,1} Q_{k 1} \rightarrow E f_{5} \\
& 1.00\left(G_{k 1}+G_{k 2}\right)+1.5 Q_{k 1}+1.5 \psi_{0,2} Q_{k 2} \rightarrow E f_{6}, 1.00\left(G_{k 1}+G_{k 2}\right)+1.5 Q_{k 1}+1.5 \psi_{0,1} Q_{k 1} \rightarrow E f_{7}
\end{aligned}
$$

The effects of combinations of permanent and variable actions have a less degrading effect on strength properties than permanent action alone, and where a combination of permanent and several variable actions is applied, the design condition will be dictated by the variable action having the shortest duration. On this basis, the modification factor corresponding to the action having the shortest duration used in the combined load case is applied to the strength property being considered. Where there is a linear relationship between actions and effects, the design condition will be that of having the largest value after division by the associated $k_{\text {mod }}$ factor. For the example given in Eq. (2.1), taking $k_{\text {mod,perm }}, k_{\text {mod,med }}$ and $k_{\text {mod,short }}$ as the modification factor for the permanent, medium-term and short-term actions, respectively, and with a linear relationship between action and corresponding stress, the design value $E_{f \mathrm{~d}}$ of effect $E_{f}$ will be the largest value given in equation (2.2):

$$
E f_{d}=\max \left[\begin{array}{l}
E f_{1} / k_{\text {mod,perm }}, E f_{2} / k_{\text {mod,med }}, E f_{3} / k_{\text {mod,short }}, E f_{4} / k_{\text {mod,short }}, \\
E f_{5} / k_{\text {mod,short }}, E f_{6} / k_{\text {mod,short }}, E f_{7} / k_{\text {mod,short }}
\end{array}\right]
$$




\subsection{Damage Models}

Damage models are used for mathematical description of the long term strength reduction as a function of stress level and duration of loading. In this paper tree damage models are fitted against the data obtained on structural timber subjected to constant loading. The characteristics of the three damage models are that $\alpha$ is defined as the degree of damage, i.e. $\alpha=0$ stands for no damage and $\alpha=1$ stands for total damage or failure.

The damage accumulation model presented by Gerhard [1] is

$$
\frac{d \alpha}{d t}=\exp \left(-A+B \frac{\sigma}{f_{0}}\right)
$$

Where $A$ and $B$ are constant, $\sigma$ is the stress and $f_{o}$ is short term strength of member.

Solution of equation (2.3) is

$$
\frac{\sigma}{f_{0}}=\frac{A}{B}-\ln \frac{10}{B} \log t=a-b \log t
$$

where

$$
a=\frac{A}{B}+\varepsilon \quad b=\frac{\ln 10}{B},
$$

end $\varepsilon$ models the model uncertainty related to the model in (2.3). $\varepsilon$ is assumed to be Normal distributed with expected value equal 0 and standard deviation $\mu$.

Assuming constant load and considering $f$ as the residual strength the solution to (2.4) is:

$$
\frac{f}{f_{0}}=\frac{1}{B} \ln (1+(1-\alpha)(\exp B-1))
$$

This expression is used when simulating the damage due to load duration.

\section{SNOW LOADS}

A stochastic model of snow load in the mountain zone in Zakopane - Tatra, Świeradów - Karkonosze, Lesko - Bieszczady is established on the basis of meteorological data IMiGW-Krakow[15], IMiGW-Wroclaw [16]. The examples of season snow loads in Zakopane, Świeradów, Lesko are shown in Figs 1, 2, 3. 


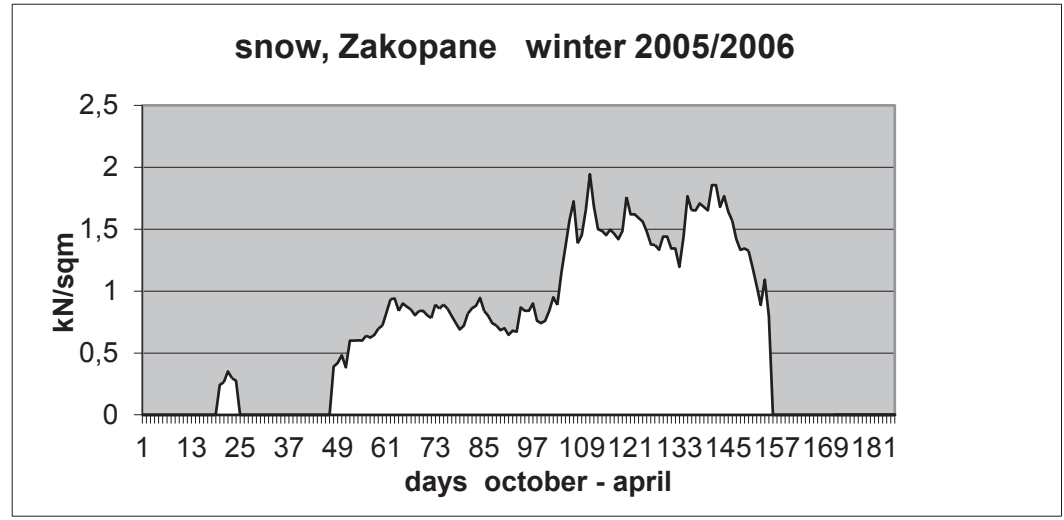

Fig. 1. Snow loads in Zakopane, Poland

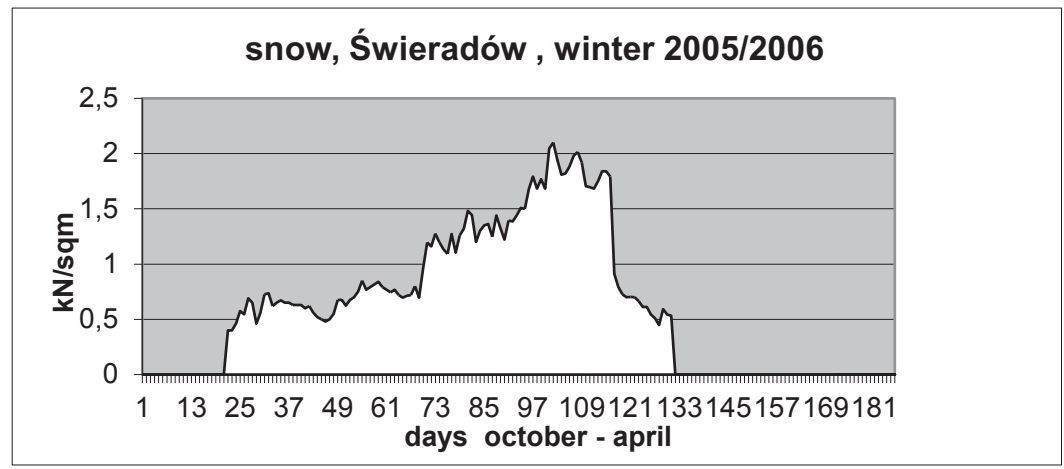

Fig. 2. Snow loads in Świeradów, Poland

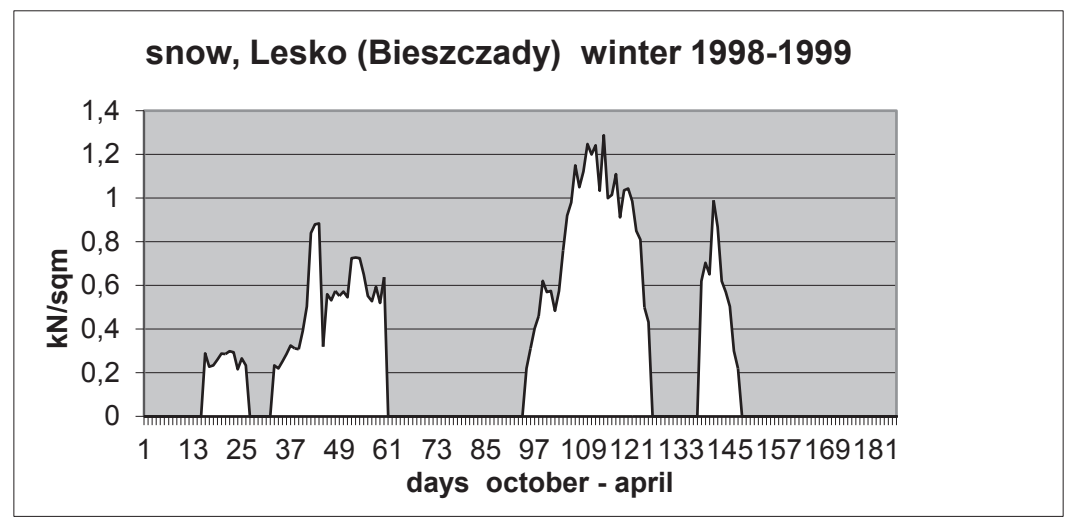

Fig. 3. Snow loads in Lesko, Poland 
A model calibrated against direct measurements of snow load is issued to transform the meteorological data into snow loads model. The load model is illustrated in Figure 4. Rectangular and triangular Sorensen, Svensson, Faber [9]

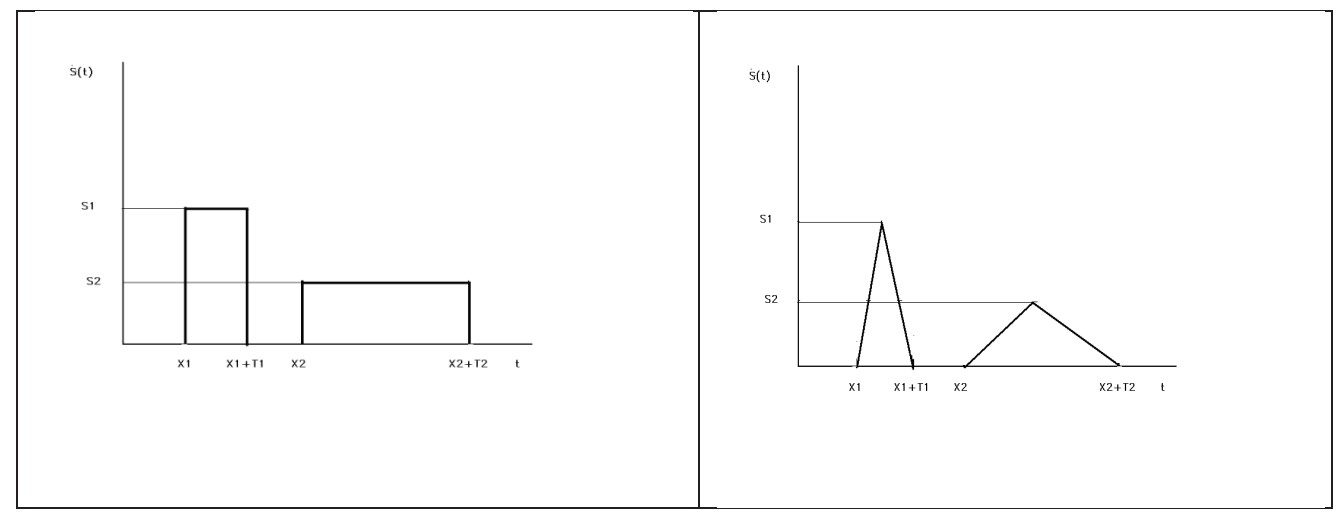

Fig. 4. Snow load models - rectangular and triangular

The snow load on terrain $S(t)$, and duration $T$ of snow packages (snow pulses) are modelled as follows:

- the occurrence of snow packages at times $X 1, X 2, \ldots$ is modeled by a Poisson process.

- The duration between snow packages is exponential distributed with expected value $1 / \lambda$, where $\lambda$ is expected number of snow packages per year

- The magnitude of the maximum snow load $P_{m}$ in one snow package (snow pulse) is assumed Woliński, Pytlowany [17] to be Gumbel distributed with expected value $\mu_{P}$ and standard deviation $\sigma_{P}$ (Figs. 5, 6, 7) 


\section{Zakopane, snow weight}

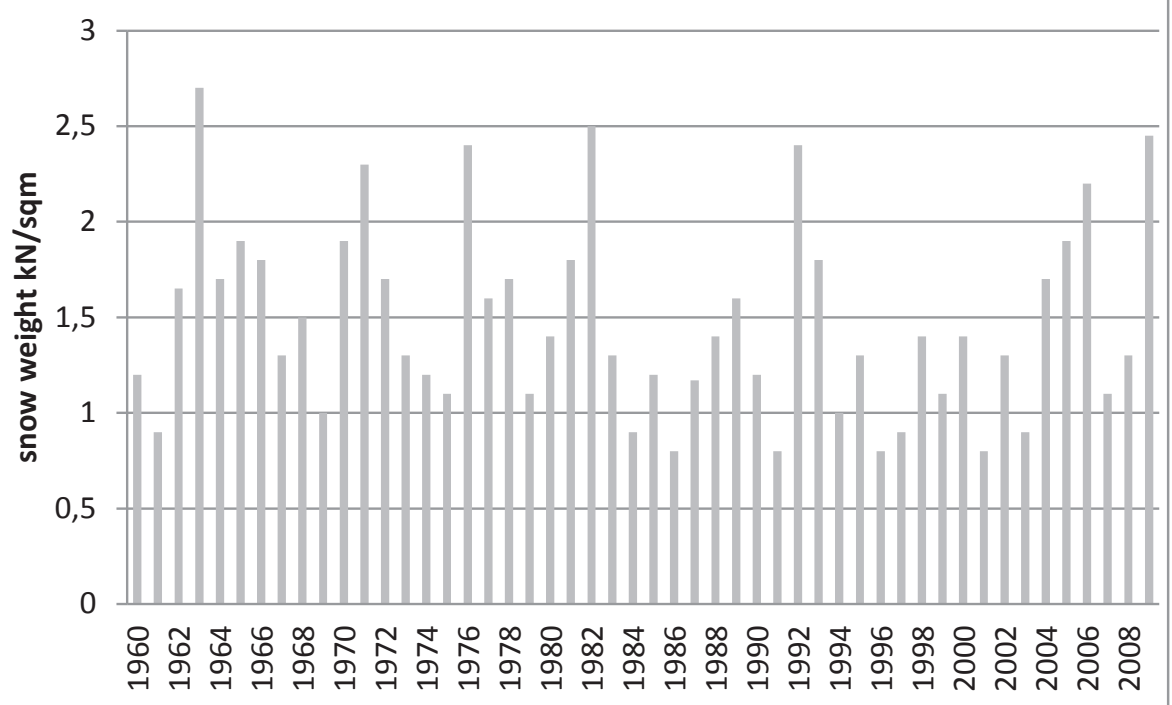

Fig. 5. Snow weight, Zakopane

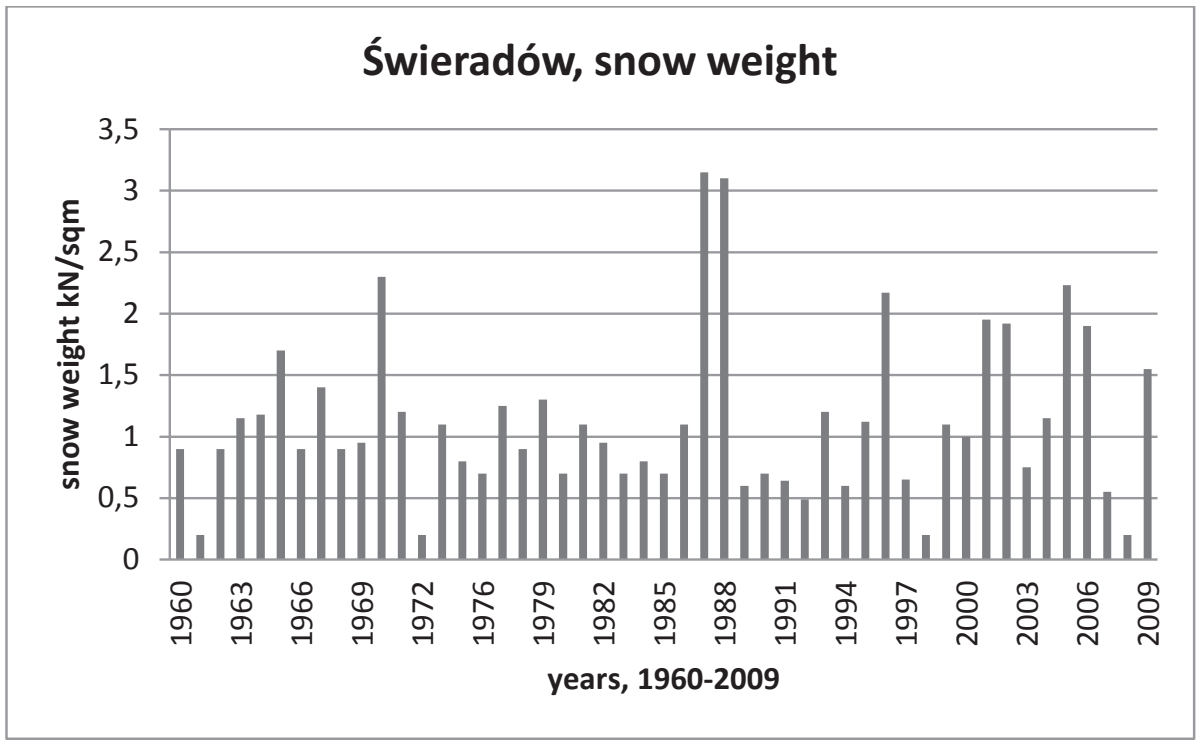

Fig. 6. Snow weight, Świeradów 


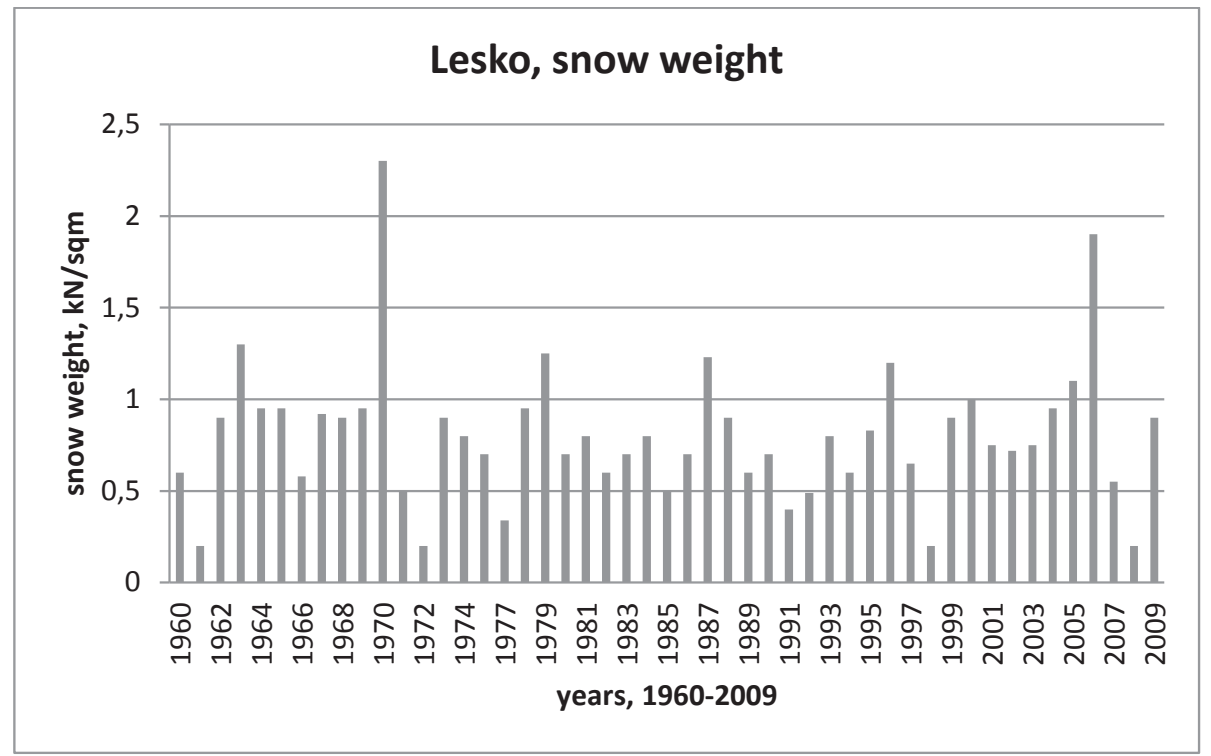

Fig. 7. Snow weight, Lesko

- The duration of a snow package $T$ is modelled by $X_{T} P_{m}$, proportional to the maximum snow load of snow package $X_{T}$ - exponential distributed with expected value $\mu_{X T}$ (Figs. 8, 9, 10)

- The time variation of snow packages is assumed to be rectangular.

The Table 2 shows probabilistic parameters of snow packets in Zakopane (Z), Swieradów (S) and Lesko (L).

Table 2.

Probabilistic parameters of snow packed load

\begin{tabular}{|c|c|c|c|}
\hline & Zakopane & Świeradów & Lesko \\
\hline$\mu_{P}\left[\mathrm{kN} / \mathrm{m}^{2}\right]$ & 1,47 & 1,12 & 0,80 \\
\hline$\sigma_{P}\left[\mathrm{kN} / \mathrm{m}^{2}\right]$ & 0,49 & 0,65 & 0,37 \\
\hline$\mu_{X T}\left[d n i /\left(\mathrm{kN} / \mathrm{m}^{2}\right)\right]$ & 65,58 & 40,97 & 53,62 \\
\hline$\lambda$ & 1,43 & 1,85 & 1,64 \\
\hline
\end{tabular}




\section{Zakopane, days with snow depths> $20 \mathrm{~cm}$}

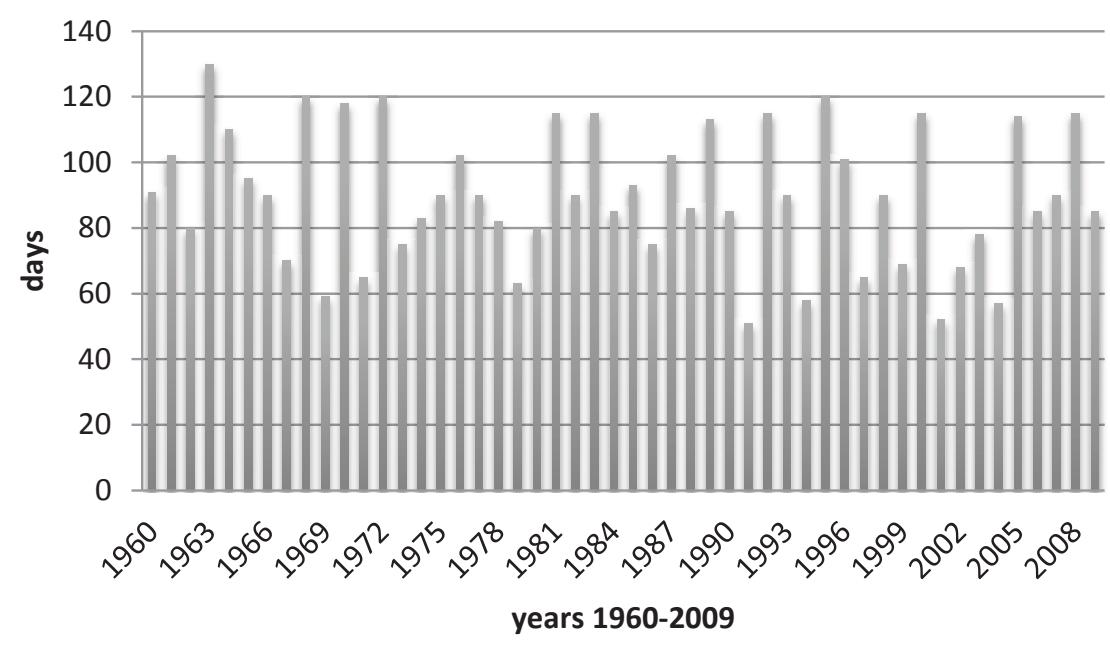

Fig. 8. Annual duration of snow load, Zakopane

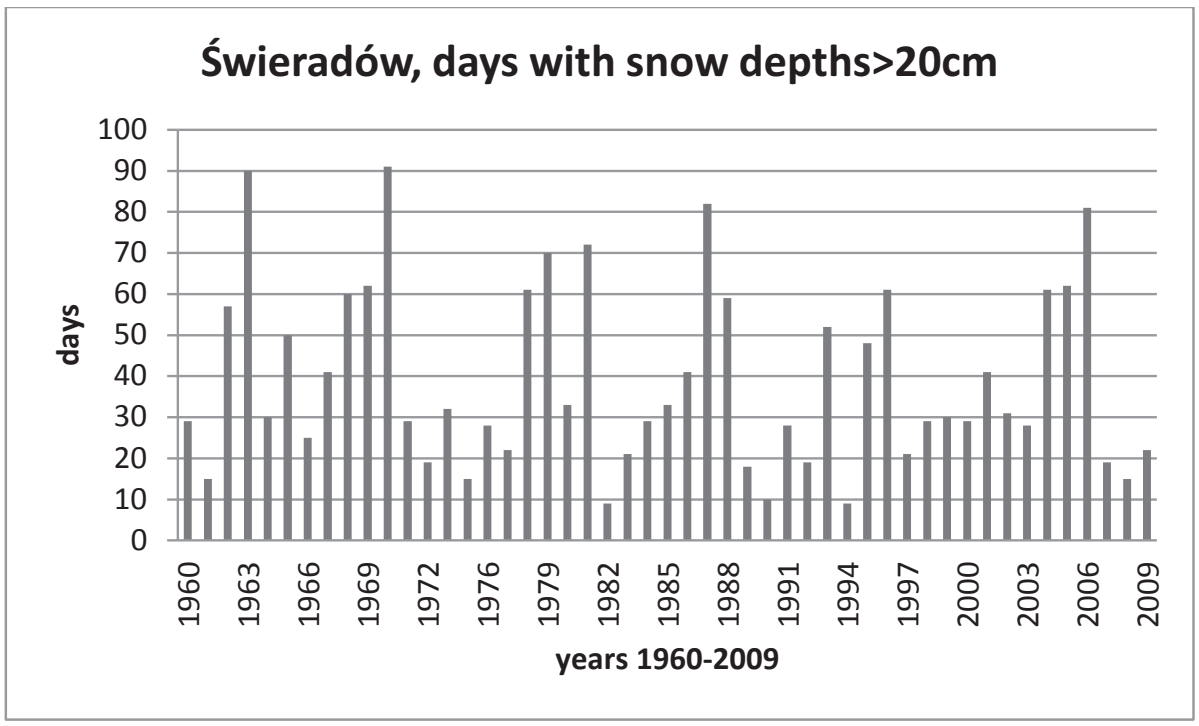

Fig. 9. Annual duration of snow load, Świeradów 


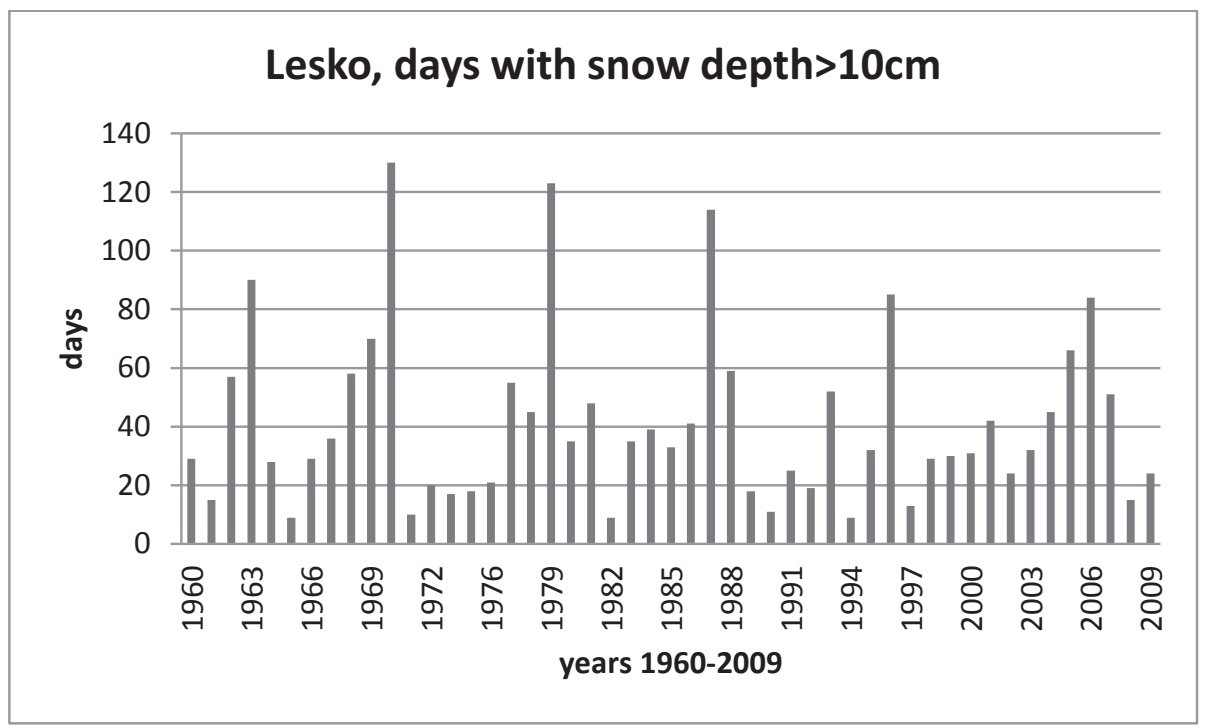

Fig. 10. Annual duration of snow load, Lesko

\section{Calibration of modification Factor $K_{\text {Mod }}$}

In the code format $E C 5$ load duration effect is represented by a modification factor $k_{\text {mod }}$. The following design equation for long-term situation can be found in the code.

$$
\frac{z f_{k} k_{m o d}}{\gamma_{m}}-\left((1-\kappa) \gamma_{G} G_{k}+\kappa \gamma_{Q} Q_{k}\right)=0,
$$

where $z$ is the design variable, $f_{k}$ is the characteristic value for short-term strength ( $5 \%$ quantile), $Q_{k}$ is the characteristic values of variable - snow load (2\% quantile), $G_{k}$ is the characteristic values of permanent load (mean value ) $\gamma_{G}$ is the partial safety factor for permanent load $(=1.35), \gamma_{Q}$ is the partial safety factor for load $(=1.5), \gamma_{m}$ is the partial safety factor for material parameter $(=1.3)$ and $\kappa$, the coefficient which represents proportion between permanent and variable loads,

The corresponding long-term limit state equation is:

$$
g=z(1-\alpha) f_{o}-((1-\kappa) G+\kappa Q) .
$$

Where $\alpha$ is damage state variable, $f_{o}$ is the short term strength, $G, Q$ are the permanent and variable - snow loads. 
For short-term situation conditions design and limit state equation the formulas can be described as follows:

$$
\frac{z f_{k}}{\gamma_{m}}-\left((1-\kappa) \gamma_{G} G_{k}+\kappa \gamma_{Q} Q_{k}\right)=0
$$

$$
g=z f_{o}-((1-\kappa) G+\kappa Q) .
$$

Where z is design parameter, $f_{o}$ - short term strength, $G$ - permanent load, $Q$ variable load .

The reliability indexes $\beta$ are calculated by simulation according to FORM method on the basis of (4.2), (4.4) and stochastic model in Table 3.

Table 3.

Stochastic model for Zakopane (Z), Świeradów (S), Lesko (L)

\begin{tabular}{|c|c|c|c|}
\hline variable & distribution & Expected value & Coefficient of variation \\
\hline$f_{o}$ timber strength & Lognormal & 1 & 0.18 \\
\hline$G$ permanent load & Normal & 1 & 0.10 \\
\hline$Q$ snow load & Gumbel & 1 & $0.34 / 0.44 / 0.46(\mathrm{Z} / \mathrm{S} / \mathrm{L})$ \\
\hline
\end{tabular}

By utilizing Monte Carlo simulation for generating random variables the modification factor $k_{\text {mod }}$

is determined according to the following procedure Sorensen, Svensson, Stang [9].

Calculate the short term reliability index $\beta s$ for a 50 year reference period using the limit state function (4.4) and the design equation (4.3). $\beta s$ is calculated as function of $\kappa$ by simulation $\left(\gamma_{G}\right.$ and $\gamma_{Q}$ are fixed).

$>$ Calculate the long term reliability index $\beta L$ for a 50 year reference period using the limit state function (14.2) and the design equation (11) and $k_{m o d}=1 . \beta L$ is calculated as function of $\kappa$ by simulation $\left(\gamma_{G}\right.$ and $\gamma_{Q}$ are fixed).

Then $k_{m o d}$ factor can be estimated as follows:

$$
k_{\text {mod }}=\frac{\gamma_{m}^{S}(\beta s)}{\gamma_{m}^{L}(\beta L)},
$$

where $\gamma_{m}^{S}(\beta S)$ is the short term partial safety factor as function of $\beta$ and $\gamma_{m}^{L}(\beta L)$ is the long term partial safety factor as function of $\beta$. 


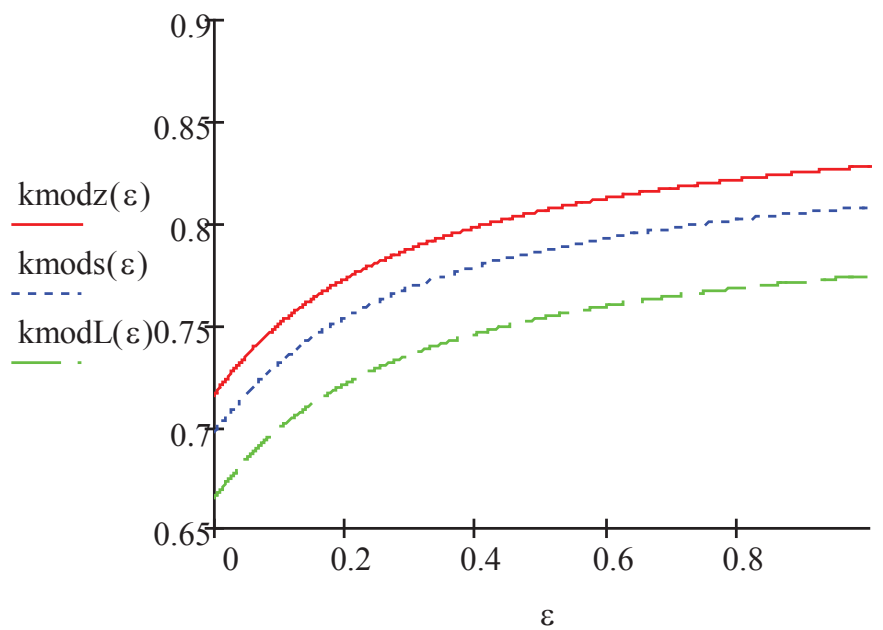

Fig. 11. Modification factor $k_{\text {mod }}$

\section{Conlusions}

The probabilistic models for the graded timber material properties have been formulated so that they readily may be applied in structural reliability analysis. It is noted that a significant effect of the time variation of snow impulses-packages on the accumulated damage model has been found. Therefore the observed snow packages are quite different and the triangular and rectangular time variations are included in the present probabilistic calibration of load duration factor. The modification factor $k_{\text {mod }}$ value depends on the ratio between permanent and variable (snow) loads significantly More research is needed on the variance parameters of snow packages loads as found in practice, and the assumption that the distribution of duration of snow packages is exponential.

\section{REFERENCES}

1. C. Gerhard, Time related effects on wood strength: a linear cumulative damage theory. Wood Sci. $1979 ; 11(3) ; 139-44$.

2. J. D. Barret, R. O. Foschi, Duration of load and probability of failure in wood. Part 1; modelling creep rupture. Can J. Civil Eng.1978;5(40);505-14.

3. R. O. Foschi, B. Folz, F. YAO, Reliability-based design of wood structures. Structural research series. Rep. no 34. Dep. Of Civil Eng., Univ. of British Columbia. Vancuver, Canada.1989.

4. D. Rosowsky, M. Bulleit, Load duration effect in wood members and connections order statistics and critical loads. Structural Safety 2002, 24(2-4), 347-362.

5. Z. KowAL, On adjusting the load bearing capacity of decisive members to reliability classes of statically determinate complex structures. Archives of Civil Engineering, LIX, 1, 2013 
6. M. MAŚLAK, Selected aspects of failure probability assessment for fire situation. Archives of Civil Engineering, LVII, 3, 2011.

7. Sz. Wolińsk, Global safety factors for nonlinear design of concrete structures. Archives of Civil Engineering, LVII, 3, 2011.

8. J. Kohler, J. Sorensen, M. Faber, Probabilistic modeling of timber structures. Structural Safety 29, 2007, 255-267.

9. J. Sorensen, S. Svensson, B. Stang, Reliability- based calibration of load duration factors for timber structures. Structural Safety 2005,27, 153-169.

10. Faber M., Kohler J., Sorensen,. Probabilistic modeling of graded timber material properties. Structural Safety 26, 2004, 295-309.

11. PN-EN 1995 Eurocode - Design of timber structures Part 1.1 General Common rules, PKN, Warsaw 2005 .

12. B. R. Ellingwood, Acceptable risk bases for design of structures. Prog. Engn Mater.2001.

13. PN-EN 1990 Eurocode -Basis of Structural Design, PKN, Warsaw 2004.

14. Porteus J., Kermani A., Structural Timber Design to Eurocode 5, Blackwell Publishing, Oxford, 2007.

15. IMiGW Kraków, Institute of Meteorology and Water Management - Krakow, Annual Snow Report 1960-2009.

16. IMiGW Wrocław, Institute of Meteorology and Water Management - Wroclaw, Annual Snow Report 1960-2009.

17. Sz. Woliński, T. Pytlowany, Evaluation of load values using the Gumbel model. Archives of Civil Engineering, LVIII, 2, 2012. 